extending from a hospital hostel, staffed by trained psychiatric nursing staff (Goldberg et al, 1985; Garety et al, 1988) up to a level of supervision and security approaching that provided by a Regional Secure Unit. Prior to the opening of a six-bedded offsite hospital hostel in 1989, each patient was assessed to establish potential suitability for transfer. Fifteen of the $\mathbf{4 2}$ cases exhibited problems which could not have been managed safely in an off-site hospital hostel. These included violence with minimal ability to collaborate in domestic activities; tendency to abscond and behave dangerously; and repeated arson.

This small group of severely disruptive patients require accommodation in a unit that offers sustained care with adequate supervision. Such a Sustained Care Unit needs to be located on a site which can contain violence. It needs trained staff; access to locked facilities for use during episodes of disturbed behaviour; and a setting sufficiently spacious to allow the residents freedom of movement. To avoid undermining self-responsibility, it is necessary to design the accommodation in a way that fosters autonomy, and to provide occupational training facilities. It is unlikely that the required level of supervision and facilities could be provided economically in a unit of less than $\mathbf{4 0}$ beds, though these might best be distributed in hostel-type buildings on a single site. That 15 cases in our sample required this level of care indicates that approximately 3.6 such beds are required per 100,000 population. Hence it would not be feasible to develop a Sustained Care Unit to serve a population of less than 1 million.

Despite attempts to prevent the accumulation of long-stay patients, a small number present problems demanding a level of care hitherto only available in a hospital setting. These new long-stay patients differ from the residual old long-stay patients in that they exhibit more violent behaviour. However, even among this group, a substantial proportion can be discharged to less intensely supervised accommodation over several years. Thus, accumulation of new cases will eventually be balanced by discharge. Although the estimates are approximate, the findings suggest that, once a steady state has been achieved, a health district serving an urban population of 300,000 would require approximately 20 beds located in hospital hostels, and access to 10 beds in a regional Sustained Care Unit. Because of the slow rate at which cases of severe, persistent mental illness accumulate, a District Health Authority can overlook the needs of these patients in the short term. However, continued failure to take account of the high level of care demanded by this small minority of patients will lead to continued failure to plan for one of the most disadvantaged groups in our society.

\section{Acknowledgements}

I am grateful to Dr K. Friston and the nursing staff who contributed to the assessments.

\section{References}

Clufrord, P. I. (1987a) Social Functioning Questionnaire. London: National Unit for Psychiatric Research and Development.

(1987b) Problems Questionnaire. London: National Unit for Psychiatric Research and Development.

Garety, P. A., Afele, H. K. \& IsAncs, I. D. (1988) A hostel ward for new long-stay psychiatric patients. Bulletin of the Royal College of Psychiatrists, 12, 183-186.

GoldberG, D. P., Bridges, K., COOPER, W. et al (1985) Douglas House: a new type of hostel ward for chronic psychotic patients. British Journal of Psychiatry, 147, 383-388.

A full list of references is available on request to Dr Liddle.

\title{
One year after the NHS Bill: the extra-contractual referral system and Henderson Hospital
}

\section{Bridget Dolan, Research Fellow in Forensic Psychiatry; and Kingsley Norton, Consultant Psychotherapist and Honorary Senior Lecturer, Henderson Hospital, 2 Homeland Drive, Sutton, Surrey SM2 5LT and Section of Forensic Psychiatry, St George's Hospital Medical School, Tooting, London SW17 0RE}

In 1991 we predicted the new contracting system introduced by the NHS Bill would reduce referrals to specialist units, particularly supra-regional units
(Dolan \& Norton, 1991), and that any resulting decline in patient numbers might lead to the suggestion that these resources were surplus to 
requirement and hence not viable in a market economy (Dolan \& Norton, 1990).

Our survey of referrers to Henderson Hospital (Dolan \& Norton, 1991) revealed how $94 \%$ of previous referrers $(71 \%$ of whom were consultant psychiatrists) said they would wish to refer clients in the future. However, $82 \%$ anticipated difficulties in obtaining funding once this had to be identified on a cost per case basis - as in extra-contractual referrals (ECRs).

Because of Henderson Hospital's small size ( 29 beds) and a maximum admission time of one year (average seven months) only a small number of patients are treated each year. A contract exists for referrals in South West Thames Region (SWT); however, those from outside SWT Region must be funded through the ECR system. Guidelines on ECR's from the Department of Health (1991a) state that ...

"the general principle to be followed is that GPs should be free, when necessary, to refer non-emergency cases ... (and that) the DHA will not challenge the GP's choice of provider unless it can be shown that the proposed referral is wholly unjustified on clinical grounds or where an alternative referrals would be equally efficacious for the patient. taking into account the patients' wishes". (Our italics; Paragraph 3.14-The NHS Management Executive (1992) have also made it clear that the same conditions as apply to a GP should apply to a referring consultant).

Since a referring DHA may not use a particular specialist service every year it will not have a regular budget or block contract for it. In our experience ECR funding often involves the referring clinician arguing each case for funding with the Director of Public Health Medicine and/or the local Contracts Manager. Some such negotiations have been acrimonious and also extremely demanding upon the clinicians' time. It has become clear that, at least some refusals to buy treatment have derived solely from a consideration of budget limitations, rather than clinical need.

In the present paper we describe Henderson Hospital's first year operating the purchaserprovider split and report our experience of the ECR system.

\section{Findings}

\section{Referral rates}

The number of referrals per year has dropped by around $25 \%$, from 216 (1989-90) and 208 (1990-91) to 155 in $1991-1992$.

In $1989 / 90$ and $1990 / 91$ approximately $35 \%$ of the total came from SWT Region. For 1991-92, 88 $(57 \%)$ referrals were extra-regional, requiring ECR funding, while $67(43 \%)$ came from SWT. In absolute numbers SWT referrals dropped by $7 \%$ (from 67 to 72), but the extra-regional referrals dropped substantially from 135 to $88(35 \%)$.

Many referrals are preceded by telephone enquiries and it may be that some potential referrers are discouraged from proceeding once they learn that ECR funding must be sought. This may apply particularly to self-referrals or referrals from nonmedical professionals $(25 \%$ of referrals in previous years). Such referrals are now problematic since funding authorities insist upon referrals being supported by a GP or psychiatrist.

\section{Cancelled referrals}

The referrer cancelled the referral before an assessment appointment was offered for $7(10 \%)$ clients from SWT, and $7(8 \%)$ extra-regional referrals. This was comparable to previous years. Two ECRs were cancelled because the referrer had lost contact with the patient after delays of 238 and 62 days respectively, waiting for a response from the funding authority.

\section{ECR funding agreement}

Of the 88 ECR requests, $32(36.4 \%)$ were agreed by 1 May 1992. The mean delay from referral to agreement was 59 days.

\section{ECR funding refused}

Nineteen referrals $(21.5 \%)$ were refused outright after an average delay of 69 days. In eight cases $(42 \%$ refusals) the reason given for refusal was financial. These included six authorities which claimed to be overspent and two which were not prepared to commit so much of their budget to one individual. Two other authorities refused to support applications made by a probation officer and a private consultant psychiatrist respectively. Another authority did not consider admission a priority for the patient. In six cases reasons for the refusal were not stated.

These refusals are despite the DOH Guidelines which state that the "DHA will not challenge the choice of provider unless it can be shown that the proposed referral is wholly unjustified on clinical grounds" (DOH, 1991a; para 3.14) and that "Every citizen has the established National Health Service right to receive health care on the basis of clinical need regardless of ability to pay" (The Patient's Charter, DOH 1991b, p. 8). Any objection to funding on financial grounds is blatantly flouting the Department of Health policy.

\section{ECR funding applications "withdrawn"}

In addition to the seven cancellations noted above, a further $11(12.5 \%)$ referrals were "withdrawn" by 
the funding authority (i.e. not the clinician) an average of 80 days after referral.

In seven cases alternative local services were apparently available although we believe that most referring consultant psychiatrists would have had comprehensive knowledge of local facilities prior to referral. In two cases the referrers wrote saying that they did not agree with the decision to use local provision.

In one withdrawn case the client had been admitted elsewhere; in another the funding authority would not support an application made by a locum consultant and in two cases the reason was given. All these responses came from the contracts manager or director of public health medicine only after we had pointed out the unacceptable delay in response.

\section{ECR decision pending}

The delay in response to ECR requests means the outcome of several ECRs is unknown at the time of writing. As of 1 May 1992, 19 (21.5\%) ECR requests from 1991-1992 were still pending although they had been under consideration for an average of 103 days.

\section{Comment}

For Henderson Hospital, the NHS new contracting system has confirmed our own predictions and those of our referrers one year ago. Referrals from outside SWT have fallen by $35 \%$ and only $36 \%$ of ECRs have been agreed in this first year of contracting. These factors have combined to reduce the number of extra-regional patients we can consider for admission by $77 \%$ from 135 in $1990 / 91$ to 32 in 1991/92.

The overall effect of the current ECR system is that Henderson Hospital has at times this year had between one and ten of its 29 beds lying empty. This contrasts starkly with the year before the new contracting system began when a waiting list for admission was in operation. Ironically, one promise of the Patient's Charter has been met, we have cut our waiting lists for treatment. However the waiting has simply been moved to another place. Patients referred to us requiring an ECR now wait an average of two months before they know whether the application has been accepted, refused or withdrawn.
In our opinion this time delay is wholly unacceptable, not only in itself, but because of the potential negative effect upon the patients' clinical state. Individuals with severe personality disorders are often highly ambivalent about accepting treatment. The referral tends to be made when their motivation is good and the likelihood of engagement in therapy is enhanced. Most referrals are tertiary and guidelines state in such cases "purchasers should recognise that the patient has already started NHS treatment and has the expectation that it will be completed" (NHS Management Executive, 1992). This guideline is obviously being ignored in several cases. The delay inherent in the ECR system means that many clients who have begun to engage in treatment may "drop out" of the system (often into another system such as the criminal justice system) and others will have lost motivation by the time assessment is offered. Thus, some re-offend in the interval between referral and response, and others remain a burden upon social and probation services. Although the delay in responding to ECR requests undoubtedly saves money for the individual funding authority concerned, the cost to the nation as a whole does not disappear.

Henderson Hospital's situation is not unique and other specialist services face similar problems. If the situation continues many will find that the purchaser-provider system makes them appear economically unviable and this may lead to their ultimate closure.

\section{References}

Department of Health (1991a) Contracts for Health Services: Operational Principles, (EL(89)MB/169) London.

(1991b) The Patient's Charter, HMSO 51-1003 10/91, London.

Dolan, B. M. \& Norton, K. (1990) Is there a need to safeguard specialist psychiatric units in the NHS? Henderson Hospital: a case in point. Psychiatric Bulletin, 14, 72-76.

- \& - (1991) The predicted impact of the NHS white paper upon the use and funding of a specialist psychiatric service for personality disordered patients Psychiatric Bulletin, 15, 402-404.

NHS MANAGement EXecutive (1992) Extra Contractual Referrals Letter from Deputy Chief Executive to all Regional General Managers 3.2.92. 